\title{
Comentario sobre la Exigibilidad de los Actos Sancionatorios de la Administración
}

\section{El Requerimiento.}

Doña María Angélicạ Sánchez Vogel, en representación de los Sres. Hernán Pfeifer F., Carlos Larraín C., Luis Fuentes D., Carmen Polanco L. y Nancy Araneda C., dedujo requerimiento de inaplicabilidad por inconstitucionalidad del art. 169 del Código Sanitario, en el recurso de amparo preventivo interpuesto ante la Corte de Santiago y en contra del Instituro de Salud Pública (Ingreso No 3.073-2009).

Dicha acción de amparo persigue que la mencionada Corte deje sin efecto seis oficios, en los que el Inscituto de Salud Pública solicita a la Intendencia Rcgional Metropolitana el arresto de los recurrentes, por vía de sustitución y apremio, por no haber pagado multas impuestas por ese Instituto, expedidos en conformidad al art. 169 del Código Sanicario, que to faculta para requerir al Intendente o al Gobernador respectivo el auxilio de la fuerza pública a efectos de realizar la detcnción del supuesto infractor y su ingreso al respectivo establecimiento penal. El arresto ances indicado fuc solicitado, no obstante hallarse pendientes sendas reclamaciones ante los tribunales comperentes. serialan los requircntes.

I.os requirentes objetan que el arresto se produce sin control judicial alguno y sin que obste a ello ha exisrencia de recursos pendientes ante los tribunales ordinarios de justicia, por aplicación de los arts. 170 y 172 del Código Sanitario. Se hace presente, además, que los requirentes no han pagado las multas que les ha aplicado la autoridad sanitaria por haberlas reclamado oportunamente, conforme a lo dispuesto en el arr. 171 del Código Sanitario. en su texto vigente con posterioridad a la sentencia de esta Magistratura, rol $N^{\circ} 1.345$, que declaró inconstitucional una de las frases del inciso primero de la misma disposición, que contenia la figura conocida como "solve et repete".

Fin definitiva, los requirentes afirman que la aplicación del art. 169 del Código Sanitario vulnetaría el inciso 4 del $\mathrm{N}^{\circ} 1$ del art. 19 de la Constitución Política de la República (C.PR), que prohibe la aplicación de todo apremio ilegítimo: las letras a) y b) del $\mathrm{N}^{0} 7$ del mismo art. 19 , en relación con lo dispuesto en el inciso 5 del $\mathrm{N}^{\circ} 3$ de ese mismo artículo, en virtud de las cualcs nadie puede ser privado de su libertad personal ni puede ésta ser restringida sino en los casos y en la forma determinados por la Constitución y las leyes, y dencro de un debido process; y el inciso 2 del art. 5 de la Carta. que establece el respeto a los derechos esencizles quc cmanan de la naturaleza humana garantizados por la Constitución, así como por los tratados internacionales ratificados por Chile y que se encuentren 
vigentes, como límite al ejercicio de la soberania, en relación con lo dispuesto en el $\mathrm{N}^{\circ} 7$ del art. 7 de la Convención Americana sobre Derechos Humanos, el cual prohíbe la privación de la libertad personal por deudas.

\section{El conflicto constitucional que conoció el Tribunal Constitucional.}

Por vía de acción de inaplicabilidad del art. 93.1, $\mathrm{N}^{\circ} 6^{\circ}$, y 11 de la CPR, la acción deducida en autos solicita la inaplicabilidad del art. 169 del Código Sanitario, en atención a que su aplicación al caso especifico de que se trata, resultaría contraria al art. $19, \mathrm{~N}^{\circ} 1$, inciso $4,3^{\circ}$, inciso $5,7^{\circ}$, letras a) y b), y al art. 5 , inciso 2 ; este último en relación con el artículo $7, \mathrm{~N}^{\circ} 7$, de la Convención Americana sobre Derechos Humanos.

El arr. 169 del Código Sanitario dispone:

"Si transcurrido el plazo señalado en el articulo anterior, el infractor no bubiere pagado la multa, sufrira, por vía de sustitución y apremio, un dia de prision por cada décimo de unidad tributaria mensual que comprenda dicha multa.

"Para llevar a cabo esta medida, el Director del correspondiente Servicio de Salud o del Instituto de Salud Pública de Cbile, en su caso, solicitará del Intendente o Gobernador respectivo el auxilio de la fuerza pública, quienes dispondrán sin más trámite la detención del infractor y su ingreso al establecimiento penal respectivo, a cuyo efecto librarán la orden correspondiente en conformidad a las reglas generales, dando cuenta de lo obrado a la autoridad sanitaria.".

\section{Lo que resuelve la sentencia.}

Por mayoría, cl Tribunal Constitucional acoge el requerimiento de inaplicabilidad por inconstitucionalidad, fundado en que el art. 169 del Código Sanitario importa:

a. El establecimiento de un apremio ilegítimo (art. $19 \mathrm{~N}^{\circ} 1$, inciso final), ya que se imponc una pena privativa de libertad por vía administrativa y sin que previamente exista una instancia jurisdiccional que revise dicha actuación (consid. 22). En efecto-dice la sentencia-, la disposición establece el castigo de una conducta que no es aún del todo reprochable, desde el momento que se ha impetrado a la jurisdicción ordinaria que determine si existe realmente una responsabilidad imputable a los recurrentes (consid. 17 y 19); que no establece la intervención de la aucoridad judicial que decrete la respectiva privación luego de determinar, conforme al mérito de un proceso, la tipicidad de la conducta, su antijuridicidad y la culpabilidad del sujeto (consid. 18); $y$ por tratarse de una sanción que no tiene fijados límites en el propio texto, todo lo cual no se condice con una medida acotada en el tiempo (consid. 20).

b. Una infracción al debido proceso (Art. $19 \mathrm{~N}^{\circ} 3$, inciso $5^{\circ}$ ): se trata de una pena que, aunque dispuesta como apremio, supone la privación de liberrad, sir que exista un proceso jurisdiccional en que se pueda defender quien será objeto de una limitación a su libertad; y porque una sanción de esta clase debe emanar de una sentencia judicial que cause ejecutoria, dictada dc 
conformidad al mérito de un justo y racional procedimiento, debidamente tramitado (consid. 25); igualmente, esta infracción se advierte de momento que la aplicación efectiva de la disposición importa reconocer como verdadera una actuación infraccional y aceptar una sanción sólo con la finalidad de no ser somerido a prisión (consid. 26).

c. Falta de proporcionalidad de la pena, al faltar una relación de equilibrio entre la sanción impuesta y la conducta imputada, especialmente porque permite consolidar irremediablemente una pena privativa de libertad, hasta por hechos de infima magnitud y en los que puede no haber mediado ni siquiera culpa del infractor (consid. 29); a mayor abundamiento pierde sentido todo el procedimiento sancionatorio seguido con antelación por la autoridad sanitaria, tendiente a garantizar que las decisiones de la autoridad se ciñan estrictamente al principio de proporcionalidad, de modo que las sanciones administrativas aplicadas se correspondan con la gravedad de las faltas cometidas y la responsabilidad de los infractores en ellas (consid. 30).

d. Se presume de derecho la responsabilidad del infractor (art. $19 \mathrm{~N}^{\circ} 3$, inciso $6^{\circ}$ ), es decir, se afecta el principio de presunción de inocencia (al afectado no se le da "trato de inocente"; concreción de la dignidad de la persona humana (art. l CPR) y del derecho a la defensa efectiva en el marco de un procedimiento justo y racional (consid. 33 y 34); en el caso del art. 169 del Código Sanitario, se permite anticipar la ejecución administrativa de una pena de prisión, antes de encontrarse firme dicha sanción, mientras los hechos que dan por establecida la infracción y por acreditada la responsabilidad se encuentran discutidos en sede judicial. De suerte que, aunque el reclamo judicial prosperc, la eventual sentencia favorable podría devenir enteramente inocua o carente de significación real, at habersc consumado antes y producido todos sus efectos irreversibles esa pena de prisión (consid. 36).

El voto de minoría es sostenido por los Ministros Sres. Francisco Fernández. F. y Carlos Carmona S., y se funda, entre otras, en las siguientes consideraciones:

a. Las disposiciones que autorizan que las decisiones administrativas se ejecuten no obstantc estar pendiente una reclamación judicial, incluyendo la sanción y su apremio, son el art. 172 del Código Sanitario y los arts. 3, inciso final, y 51 de la Ley de Bases de los Procedimientos Administrativos (LBPA), las que no fueron objeto del requerimiento.

b. La ejecutoriedad del acto administrativo, consagrada en diversos textos legales, no se contrapone con la Constitución. Ella se funda en la necesidad de que el Presidente de la República, y los órganos que colaboran con él, es decir, los órganos de la Administración del Estado, lleven a cabo adecuadamente la labor de gobierno y administración (arts. 24 y 38 C.PR), en cjercicio del mandato constitucional de hacer realidad el "bien común" y "servir a la persona humana".

c. La Constitución ha reservado al legislador la regulación de las formas en que deben desenvolverse los procedimientos administrativos y judiciales (art. $19 \mathrm{~N}^{\circ} 3$, inciso $5^{\circ}$, art. $63 \mathrm{~N}^{\circ} 3$ y $\mathrm{N}^{\circ} 18$, art. 65 , inciso 4", $\mathrm{N}^{\prime \prime} 2$ ). En cumplimiento del mandato del artículo $63 \mathrm{~N}^{\circ} 18$, el legislador puede regular los efectos de un acto que surge a consecuencia de la tramitación de un procedimiento administrativo, como efectivamente lo ha hecho en la I.BPA, incluyendo entre estos efectos la ejecutoriedad. 
d. La garantía que tienen los particulares frente al efecto ejecutorio del acto administrativo es solicitar la suspensión del mismo, en sede administrativa o jurisdiccional. Esa suspensión puede solicitarse en cualquier tipo de procedimiento administrativo o jurisdiccional, pues ésta pucde ser dispuesta "por la autoridad administrativa dentro del procedimiento impugnatorio, o por el juez, conociendo por la vía jurisdiccional" (art. 3, inciso final, LBPA).

e. A la multa administrativa no le es aplicable el art. 79 del Código Penal, que establece que "no podrá ejecutarse pena alguna sino en virtud de una sentencia ejecutoriada". Esta multa es antes que todo un acto administrativo $y$, como tal, requiere de un procedimiento administrativo previo (arss. 28 y 29 LBPA), que la resolución que la aplica esté fundada (art. 11 LBPA) y que no sea retroactiva (art. $52 \mathrm{LBPA}$ ).

f. El art. 169 del Código Sanitario no establece una "prisión", sino que se trata de un "arresto": no es una pena penal, que no busca forzar a nadie a hacer algo, que exige un jue $z$ que la imponga y que no se puede suspender. Tratándose de un "arresto", el art. 169 contiene un apremio destinado a cumplir una obligación legal no satisfecha por el sujeto pasivo de ella, que bien puede imponer la Administración previa habilitación legal, que se puede suspender por vía de recurso impugnaticio, y que se extingue por el pago de la multa administrativa.

g. El art. $19 \mathrm{~N}^{\circ} 7$, lerra c) CPR, señala que la orden debe ser impartida por uп "funcionario público expresamente facultado por la ley", o por "la autoridad". No habla de que el arresto sea dispuesto por un juez de manera exclusiva. Al contrario, cuando trata, por ejemplo, de la prisión preventiva, obliga a que ésta deba ser considerada por un juez y sólo por éste, para ponderar si su mantención es o no necesaria para la investigación o para la seguridad del defendido o de la sociedad (articulo $19 \mathrm{~N}^{\circ} 7$, lerra e).

h. El Tribunal Constitucional ha considerado ajustada a la Constitución una norma que mantienc la prisión preventiva, es decir, una privación de libertad, aunque no exista una decisión judicial con fuerza de cosa juzgada (STC Rol 1001-2007, de 29.01.2008, considerandos $8^{\circ}, 21^{\circ}, 22^{\circ}$ y $23^{\circ}$ ). Incluso más, en esa misma sentencia este Tribunal consideró que esa norma era constitucional a pesar de que hubiera un pronunciamiento judicial en contra de la prisión preventiva. Otorgar mayores garantías en cl proceso sancionador administrativo que en el proceso penal, va en contra de la correcta interpretación de la Constitución y de la jurisprudencia constante del Tribunal.

\section{Comentarios.}

1. Ha sido una constante histórica que el poder público, ejercido en cualquiera de sus manifestaciones, represente para la persona común y corriente un poder superior de dominación, al que solamente cabe someterse. Sucede que ello ya no es concebible en iguales términos. Una verdadera tutela judicial efectiva se transforma en piedra angular de protección de los derechos e intereses legítimos de los ciudadanos, y una Constitución con plena vigencia y de aplicación inmediata, hace funcionar efecrivas instancias de control intrasistémicas: el Tribunal Constitucional cstá a cargo de vigilar la contención de la legislatura a la Constitución; la Contraloría General de la República hace lo propio respecto de gran parte de la actividad de la Administración, y la Cortc Suprema -en cuanto tribunal de casación- vigilando el ejercicio de la función jurisdiccional. 
Porque en el Estado Constitucional, Social y Democrático chileno, la justificación y legitimación del ejercicio del poder público tiene una estrecha conexión con los derechos fundamentales de las personas (arts. 5.2 y $19 \mathrm{CPR}$ ); pero no en la perspectiva de lucha entre las personas vs. el Estado, sino que sobre el mayor, menor o nulo ámbito decisorio que tienen los órganos colegisladores, ejecutivo y tribunales respecto de la forma e intensidad como pueden ser afectados o limitados esos derechos fundamentales de las personas, sin infringir la Consticución. En palabras de Juan Miguel de la Cuétara, "los derechos fundamentales son parte esencial del sistema de juridiciación material del poder, que todos los operadores jurídicos deben respetar y aceptar." (Las potestades administrativas, 1986, p. 28).

Sabemos que ese poder, en cuanto refleja la idea de orden o mandato y de obligatoziedad, es el máximo poder concebible (Leisner, Die undefinierbare Verwaltung, 2002, p. 21). Sin embargo, dicho poder no llega a ser absoluto, puesto que se equilibra con el reconocimiento de los derechos esenciales de las personas y con la creación de garantías efectivas de protección de ellos, logro alcanzado durante la segunda mitad del siglo XX, y que ha redundado en lo que se conoce como la subjetivización y sensibilización del Derecho Público. Subjetivización, en cuanto reconoce a dichos derechos subjetivos un lugar preponderante, y sensibilización, ya que toma en consideración los incereses privados y la forma como ellos son afectados en intensidad, amplitud y profundidad por actos y decisiones de los poderes públicos (Schmidr-Assmann, Das allgemeine Verwalingsrecht als Ordnungsidee, 1998, p. 57).

En este proceso de depuración y legitimación de ciertos privilegios históricos de ła Administración, sobresalen en las materias laboral y sanitaria las sentencias del Tribunal Constitucional pronunciándose sobre el "solve et repete" (paga primcro y reclama después), y declarando inaplicables por inconstitucionales disposiciones legales que restringen el acceso a la jurisdicción, al ser barreras injustificadas y carentes de razonabilidad al Derecho a la Justicia (art. $19 \mathrm{~N}^{\circ} 3 \mathrm{CPR}$ ). Por ejemplo, STC 946, 968, 1332, 1356, 1382, 1391, 1418, 1470. Especial mención, por su relación con la sentencia que comentamos, debe hacerse de la STC 1345 que privó de validez general a la última parte del inciso 1 del art. 171 del Código Sanitario, que explícitamente exigía, como requisico para dar curso al reclamo que pudiere interponer un afectado, "... que el infractor acompañe el comprobante de haber pagado la multa."

2. Io que resuelve la sentencia se enmarca perfectamente en el fenómeno de hacer horizontal la posición de la persona humana frente al poder público (I.); pero ello por sí solo no alcanza a ser fundamento suficiente de la decisión judicial adoptada; los argumentos del voto de mayoría no son directos ni concluyentes, pareciendo ser desarrollado para unas circunstancias de hecho y de derecho que no les acompañan.

Primero que todo, el art. 169 del Código Sanitario no establece una pena ni un castigo; se trana más bien de un apremio contra el administrado que no da cumplimiento oportuno a un acto administrativo que resulta de una investigación administrativa, que es dictado por la autoridad competente y que, por último, produce inmediata exigibilidad (art. $19 \mathrm{~N}^{\circ} 7$ letra b) CPR). La drasricidad que manifiesta el arresto, en comparación con otras medidas administrativas de apremio (v.gr.: requerimiento, embargo y ejecución, auxilio de la Fuerza Pública, etc.), no prueba per sc una afectación a la libertad de una persona excediéndose lo permitido constitucionalmente, si 
es que la medida es adoptada por orden de funcionario público expresamente facultado por la ley y después de que dicha orden sea intimada al afectado en forma legal (art. $19 \mathrm{~N}^{\circ} 7$ letra c) CPR).

Luego, tampoco se echa en menos que en el caso no exista una instancia jurisdiccional que pudiere revisar la aplicación del apremio. A decir verdad, las garantías están otorgadas por el art. $19 \mathrm{n}^{\circ} 7$, letra c), inciso $2^{\circ} \mathrm{CPR}$, de obligado cumplimiento por la autoridad administrativa: "Si la autoridad hiciere arrestar o detener a alguna persona, deberá, dentro de las cuarenta y ocho horas siguientes, dar aviso al juez competente, poniendo a su disposición al afectado."

Esto hace concluir, consecuencialmente, que tampoco se configuraría una infracción al debido proceso (art. $19 \mathrm{~N}^{\circ} 3$, inciso $5^{\circ}$ ), primeramente, porque la medida, al ser un apremio, que no una pena, no exige una previa sentencia judicial (art. 79 Código Penal), sino que le son aplicables, más bien, las formalidades establecidadas en la LBPA para los actos administrativos que limiten derechos de los particulares, esto es, la adopción de la resolución que sirve de fundamento a ella y notificación previa al particular (art. 50). Recordemos que en Chile, a diferencia del caso español, por mencionar un ejemplo, la Carta Fundamental no establece explícitamente una prohibición para la Administración de adoptar decisiones que directa o subsidiariamente impliquen una privación de la libertad (art. 25, parágrafo 3 Constitución Espańola). Por lo mismo, la supuesta reserva judicial en esta materia, que enuncia el Tribunal, verdaderamente no está consagrada en la Carta.

En seguida, porque el afecrado no tan sólo cuenta con una acción de impugnación que pueda hacer valer en contra de la medida ante la justicia ordinaria civil, sino porque cn esa sede puede solicitar medidas cautelares tendentes a suspender la ejecución de la sanción o la aplicación del apremio (arts. 3 , inc. $7^{\circ}$ y $57 \mathrm{~L} . \mathrm{BPA}$ ); mismas que los requirentes se han abstenido efectivamente de solicitar ante el juez comperente.

Finalmente, porque el reproche que contiene la sentencia de que "pierde sentido todo el procedimiento sancionatorio seguido con antelación por la autoridad sanitaria, tendiente a garantizar que las decisiones de la autoridad se ciñan estrictamente al principio de proporcionalidad", no es tal, ya que la proporcionalidad es una cualidad predicable directamente de la sanción administrativa, que en este caso se expresa en una multa en dinero, que ha sido dererminada como resultado de un procedimiento administrativo sancionatorio, en que los afectados han podido ejercer su derccho de defensa, y cuyo importe se enmarca dentro de unos valores minimos y máximos expresamente permitidos por la ley (art. 174 Código Sanitario). I’or ello, el apremios, a decir verdad, guarda directa relación con el importe final de la sanción administrativa: un día de prisión por cada vigésimo de sueldo vital mensual (art. 169, inc. $1^{\circ}$ Código Sanitario).

3. Pocos paises reconocen el efecto suspensivo automático del recurso contencioso administrativo (v.g r.: Alemania, Austria y Finlandia) (Sommermann, El papel de la ley alemana de la justicia Administrativa para la realización del Estado de Derecho, 2009, p. 9). Por el contrario, la regla general a nivel comparado, de la cual el caso chileno es parte, dispone que el acto administrativo debe producir sus efectos y consecuencias jurídicas no obstante encontrarse impugnado; salvo medida cautelar expresamente dispuesta por la autoridad administrativa o por el juez. En este sentido, nuestro sistema administrativo sigue de cerca al francés, sustentado en la lógica de la presunción de legalidad del acro administrativo, pero otorgando al juez la facultad de dictar 
medidas de urgencia (référés), especialmente, de suspensión de la decisión (CAPITANT, Punto de vista francés sobre la ley alemana de la Justicia Administrativa (VwGO), 2009, p. 112).

La sentencia del Tribunal Constitucional, que comentamos, al declarar la inaplicabilidad del art. 169 del Código Sanirario, establece consecuencialmente una regulación especial diversa dentro del sistema administrativo chileno, a saber, impedir la concreción de una medida de apremio activada por no haberse dado cumplimiento a lo resuelto por la Administración, cuando aquélla supone privar de libertad a una persona, quien no ha solicitado medida cautelar alguna en el proceso judicial de revisión abierto al efecto. Esta era la misma propuesta legislativa contenida en el antiguo Proyecto de Ley que establece las Bases de los Procedimientos Administrativos Sancionatorios, de marzo 2004 (Boletín 3475-06), y que fuera archivado en agosto del 2006. De entre sus normas sobresalían las siguientes ideas: (1) las sanciones que impongan multa serán siempre reclamables y no serán exigibles mientras no esté vencido el plazo para interponer la reclamación, o ésta no haya sido resuetra; (2) la prohibición de que la sanción administrativa pueda traducirse directa o indirectamente en privación de libertad; (3) excepcionalmente no caben medidas de suspensión de los efectos del acto reclamado, cuando aquéllo pueda afectar la seguridad o salubridad de las personas $y$, en general, cuando concurran circunstancias de daño o peligro inminente que exijan su inmediata corrección.

Entonces, estimamos que en la S'IC1518-09-INA, por vía de una acción de inaplicabilidad por inconstitucionalidad, se suple judicialmente una voluntad legislativa inexistente; misma omisión normativa que el Tribunal Constitucional ya había reprochado del Poder Legislativo en sus STC 376 y 389 , ambas de 2003, y que fueron motivo para que el P'residente de la República despachara en su momento al Senado el mensaje del proyecto de ley antes indicado.

Más en detalle, la situación nos permite apreciar las siguientes dos cuestiones.

La primera dice relación con la conducta abstencionista que muestra muchas veccs el Lcgislador chileno. Fste reproche es ejemplificable con las ocasiones en que ha delegado en altos tribunates de justicia la competencia para disponer regulaciones procesales (cuya constitucionalidad cs altamente discutible) y, también, como en este caso, cuando no legisla sobre materias que, de suyo, caen en su propio y natural ámbiro comperencial. Sobre este parricular, es digno de recordarse la intervención del dipurado Sergio Flgueta, cuando en la sesión del Congreso Pleno, de $13 \mathrm{dc}$ febrero de 1994, recordaba las siguientes palabras del insigne historiador, Sr. Gonzalo Bulnes: "el Parlamento influye en la marcha del Estado por lo que hace y por lo que impide hacer. Si queréis conocer la acción de un Congreso, no la midaiis sólo por las leyes que dicta. Estudiad su archivo para saber lo que encarpera y no discure. De ordinario tiene menos importancia lo que hace que lo que evita". (HdL N 19.295 , p. 75 y s.).

La segunda cuestión relevante, nos parece ser la propia decisión del Tribunal Constitucional: se hace decir a la Constitución algo que en realidad no dice, porque en el fondo subyace una crítica a la bondad de la ley: juicio negativo a la decisión legislativa -la del art. 169 del Código Sanitario-, que contiene un "desusado privilegio" (consid. $7^{4}$ ), antes que una atribución que derecha y evidentemente atente contra la Carta Fundamental. Sin embargo, la necesaria deferencia que debe mostrar el Tribunal frente al Legislador no lo faculta para declarar inaplicable por inconstitucional una norma legal antipática. 